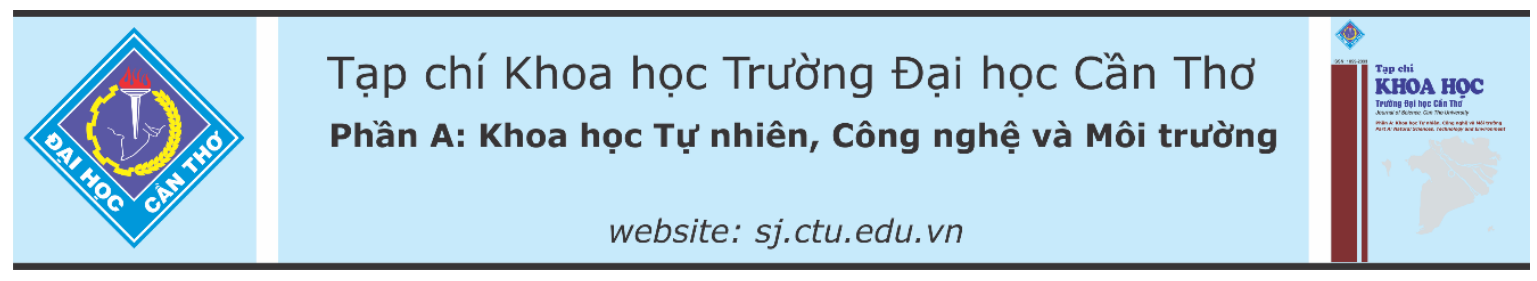

DOI:10.22144/ctu.jvn.2021.113

\title{
ÚNG DỤNG SẢN PHẨM ẢNH CHỈ SỐ DIÊN TÍCH LÁ (MODIS LAI) VÀ HÊ THỐNG QUAN TRẮC DỮ LIỆU THỜI TIỂT TRONG MÔ HİNH ƯớC ĐOÁN NĂNG SUẤT LÚA
}

\author{
Trương Chí Quang*, Lê Vũ Bằng và Võ Quang Minh \\ Khoa Môi truờng và Tài nguyên Thiên nhiên, Truoòng Đại học Cần Tho' \\ *Nguoòi chịu trách nhiệm về bài viết: Truoong Chi Quang (email: tcquang@ctu.edu.vn)
}

\section{Thông tin chung:}

Ngày nhận bài: 07/02/2021

Ngày nhận bài sủa: 11/05/2021

Ngày duyệt đăng: 20/08/2021

Title:

Applying MODIS Leaf Area

Index products and

meteorological data

monitoring systems for

estimating rice yields

\section{Tù khóa:}

Chỉ số diện tích lá, IOT, MODIS LAI, Oryza 2000, uóc đoán năng suất lúa

\section{Keywords:}

Leaf Area Index, MODIS LAI, IOT, Oryza 2000, rice yield estimation

\begin{abstract}
The study aims to assess the possibility of using the Leaf Area Index (LAI) MODIS product and IOT weather data to estimate rice yield at pixel level. MODIS LAI images (product MCD15A2Hv006) acquired at 30 to 40 days after-sowing were aggregated to construct the LAI map for each rice season cropping. The LAI values were converted to relative leaf growth values (RGRL) which were used in the Oryza2000 v3 model to simulate rice yield. The model was calibrated using the data from the season Summer-Autumn 2018. The estimated results were then compared with the statistics-based yield data of the Autumn-Winter 2018, Winter-Spring 2018-2019 and Summer-Autumn 2019 cropping seasons with RMSE values of 0.44 ton, 0.38 ton and 0.31 ton accordingly with nRMSE values of $5.61 \%, 4.22 \%$ và $5.40 \%$. In general, the results obtained show that MODIS LAI product could help to build detailed pixel-level yield estimation maps through a simple image processing method that can be applied for agricultural managers.
\end{abstract}

\section{TÓM TẮT}

Bài viết nhằm đánh giá khả năng ưng dụng ảnh viễn thám chi số diện tích lá MODIS LAI và dĩ liệu thời tiểt thu thập bằng IOT trong ước đoán năng suất lúa dựa trên pixel ảnh. Phuoong pháp nghiên cưu dựa trên nguồn ảnh MODIS LAI MCD15A2Hv006. Bản đồ diện tích lá mỗi vu được tổng hơp tù các ảnh LAI ưng với thời điểm 30-40 ngày sau sạ cho tùng đơt sạ. Giá trị LAI được chuyển đổi thành hệ số phát triển tuoong đối của lá (RGRL) sử dụng cho mô hình Oryza2000 v3 để uớc đoán năng suất lúa. Mô hình được hiệu chinh dựa vào năng suất lúa vu Hè Thu năm 2018 để làm cơ sở ước tính cho các vu còn lại. Với các tham số được hiệu chỉnh, năng suất mô phỏng được kiểm chứng cho vu Thu Đông 2018, Đông Xuân 20182019 và Hè Thu 2019 với sai số RMSE lần luợt là 0,44 tấn, 0,38 tấn và 0,31 tấn turong ứng với $n R M S E$ là $5,61 \%, 4,22 \%$ và $5,40 \%$. Kết quả đạt được cho thấy ảnh MODIS LAI giúp xây dựng bản đồ ước đoán năng suất chi tiết mức pixel nhò̀ vào phương pháp xủ lý ảnh đơn giản, dễ triển khai ưng dụng cho các nhà quản lý trong việc phát triển sản xuất nông nghiệp. 


\section{GIỚI THIỆ}

Sản xuất lúa đóng vai trò quan trọng trong cơ cấu sản xuất nông nghiệp của Việt Nam, do đó việc ước đoán trước được sản lượng lúa dựa vào dữ liệu sinh trưởng và dữ liệu thời tiết giúp việc quản lý sản xuất nông nghiệp được kịp thời, dự kiến được sản lượng lương thực từ giữa vụ để có kế hoạch tiêu thụ. Tuy nhiên chi phí cho việc điều tra thực tế về sinh trưởng của cây lúa mất nhiều thời gian và nguồn nhân lực.

Hiện nay, dữ liệu ảnh viễn thám quang học đã được sử dụng rộng rãi nhằm mục đích giám sát và ước lượng năng suất trên thế giới và ở Việt Nam. Theo Lam-Dao et al. (2009), dữ liệu ảnh viễn thám thích hợp cho việc giám sát nông nghiệp nói chung và giám sát cây lúa nói riêng ở vùng nhiệt đới như ở Việt Nam.

Bên cạnh đó, với sự phát triển mạnh mẽ của mô hình dự báo, việc dự báo trước những rủi ro, những thiệt hại cũng như ước đoán năng suất lúa đã được thực hiện bởi nhiều nghiên cứu với cả ảnh quang học và ảnh Radar. Nhiều tác giả đã dùng ảnh Radar để theo dõi thời điểm gieo sạ (Nelson et al., 2014; Phung et al., 2020), xác định thời điểm sinh trưởng mạnh nhất của cây trồng đỉnh sinh trưởng và tính tương quan chỉ số sinh trưởng của lúa với ảnh. Đối với ảnh quang học, Dương Văn Khảm (2011) đã xây dựng mô hình dự báo năng suất, sản lượng lúa ở Đồng bằng sông Hồng bằng dữ liệu ảnh MODIS NDVI.

Mô hình Oryza 2000 (Bouman et al., 2001) sử dụng dữ liệu thời tiết hàng ngày, dữ liệu canh tác, dữ liệu đất và chỉ số diện tích lá để mô phỏng, thời gian sinh trưởng của cây lúa, thời gian bắt đầu các giai đoạn sinh trưởng. Chỉ số diện tích lá (LAI) là tổng diện tích một mặt của mô lá trên một đơn vị diện tích mặt đất. Nó đặc trưng cho khả năng tiếp xúc giữa tán lá và khí quyển, nơi diễn ra hầu hết các hoạt động quang hợp, trao đổi năng lượng (Breda, 2003). Chỉ số LAI biến động trong cả thời kỳ sinh trưởng, việc xác định chỉ số LAI cho mô hình khá tốn kém nếu đo đạc từ thực địa. Ảnh viễn thám MODIS LAI MCD15A2Hv006 (Myneni et al.,
2015) có độ phân giải thời gian 8 ngày cung cấp đầy đủ các thông tin chỉ số diện tích lá trên diện rộng giúp tiết kiệm chi phí và rút ngắn thời gian xử lý so với phương pháp đo đạc thực địa. Trong điều kiện nguồn ảnh MODIS LAI có sẵn và phương pháp xử lý ảnh radar phức tạp đối với người dùng, chưa có nhiều nghiên cứu dùng sản phẩm MODIS LAI. Do đó trong nghiên cứu này, sản phẩm MODIS LAI được sử dụng kết hợp với chỉ số quan trắc thời tiết tự động từ thiết bị IOT (Internet of things) và mô hình Oryza 2000 để ước đoán năng suất lúa trong trường hợp nghiên cứu ở tỉnh An Giang.

\section{PHƯƠNG PHÁP NGHIÊN CÚU}

Phương pháp nghiên cứu được thể hiện một cách tổng thể thông qua sơ đồ ở Hình 1 . Ảnh viễn thám MODIS LAI phiên bản MCD15A2Hv006 được thu thập từ nguồn https://earthexplorer.usgs.gov/ do trung tâm LP DAAC của NASA phân phối (Myneni et al., 2015). Dữ liệu thu được từ ngày $01 / 01 / 2018$ đến ngày 30/12/2019, mã loại ảnh là MODIS MCD15A2H V6, vị trí ảnh tải xuống tại khung ảnh V8 H28. Ảnh LAI có độ phân giải khổng gian 500 $\mathrm{m}$, độ phân giải thời gian 8 ngày, được cắt theo ranh giới tỉnh An Giang bằng phần mềm QGIS.

Dữ liệu thời tiết hằng ngày gồm nhiệt độ cao nhất, nhiệt độ thấp nhất, lượng mưa, áp suất không khí, số giờ nắng và độ ẩm không khí được thu thập từ thiết bị quan trắc IOT đặt tại tọa độ (10.486941,105.183807) thuộc xã Bình Phú, huyện Châu Phú, tỉnh An Giang.

Dữ liệu về phương thức canh tác canh tác lúa, giống lúa, đất, độ mặn đất ở độ sâu $0-20 \mathrm{~cm}$ được thu thập từ dự án RIICE và các mô hình mẫu của Oryza.

Dữ liệu bản đồ đợt sạ là cần thiết cho việc lập mô hình mô phỏng năng suất lúa. Tuy nhiên, mục đích chính của nghiên cứu là đánh giá khả năng ứng dụng của sản phẩm LAI trong mô hình mô phỏng năng suất lúa. Bên cạnh đó bản đồ đợt sạ tin cậy cao từ nguồn ảnh Sentinel-1 (Holecz et al., 2013) vì thế nghiên cứu sử dụng bản đồ đợt sạ được xây dựng từ phần mềm thương mại MapScape 5.5 để loại bỏ các sai sót do bản đồ ngày sạ từ ảnh MODIS. 


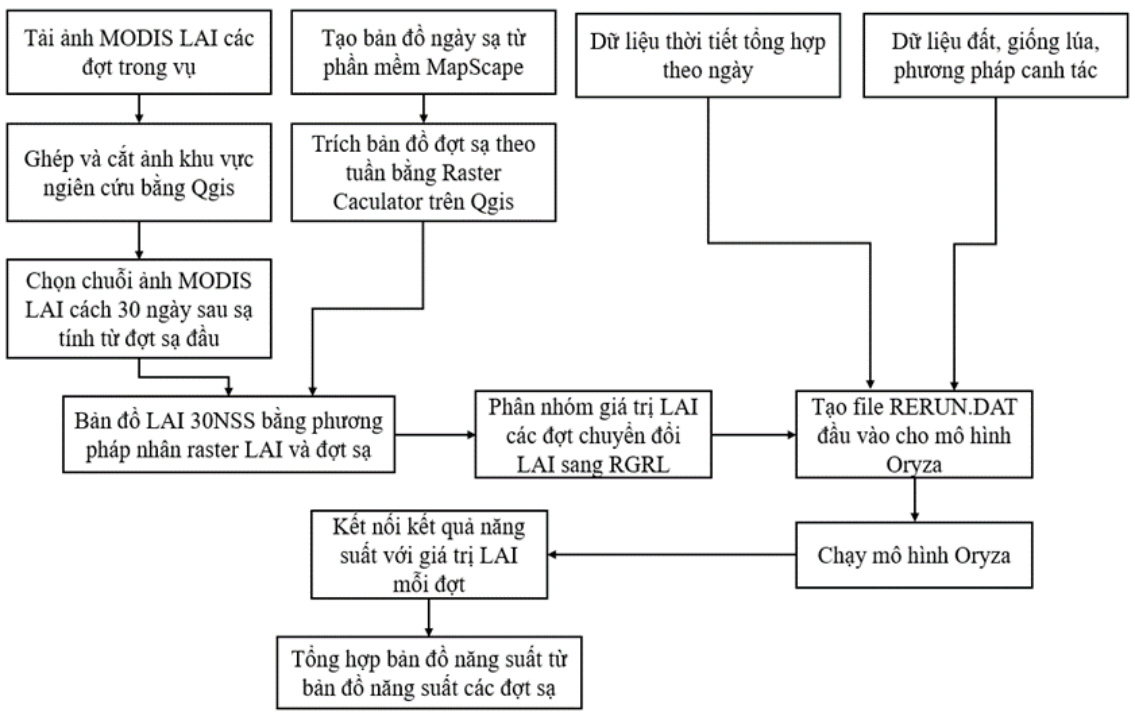

Hình 1. So đồ tổng quát phương pháp thực hiện

\subsection{Phương pháp xử lý ảnh chỉ số diện tích lá MODIS-LAI}

Số liệu bản đồ của vùng nghiên cứu được thu thập và biên tập trong cơ sở dữ liệu GIS thống nhất về cấu trúc hệ tọa độ, hệ quy chiếu. Sử dụng phần mềm QGIS để xây dựng và hoàn thành bản đồ diện tích vùng trồng lúa bản đồ năng suất lúa.

Để ước đoán được năng suất lúa dựa vào chỉ số LAI, cần xây dựng bản đồ chỉ số diện tích lá ở thời điểm $1 / 3$ chu kỳ sinh trưởng của cây lúa theo cách tính của Setiyono et al. (2019) đây là thời điểm cây lúa hoàn thành giai đoạn đẻ nhánh, diện tích lá ổn định. Thời điểm này cũng thích hợp để dự báo khi vụ lúa chưa kết thúc. Do đó, với giống lúa ngắn ngày 95-100 ngày, các thời điểm lúa 33 đến 40 ngày sau sạ (NSS) được chọn.

Phần mềm MapScape 5.5 và nguồn ảnh Sentinel-1 được dùng để xây dựng được bản đồ các đợt sạ với ưu điểm có độ chính xác và độ phân giải cao $(20 \mathrm{~m})$. Trên cơ sở bản đồ đợt sạ, các ảnh MODIS LAI ở các thời điểm $1 / 3$ thời gian sinh trưởng (thời điểm 33-40 NSS tính từ thời điểm bắt đầu đợt sạ) được chọn để trích ra giá trị LAI. Các giá trị này tổng hợp lại để được bản đồ LAI ở $1 / 3$ chu kỳ sinh trưởng. Tuy nhiên, do sản phẩm MODIS LAI được tổng hợp 8 ngày/ ảnh và độ phân giải thấp $(500 \mathrm{~m})$ nên bản đồ được lấy mẫu lại thành $20 \mathrm{~m}$ phù hợp với độ phân giải của bản đồ đợt sạ được xây dựng từ phần mềm MapScape.

\subsection{Xác định chỉ số phát triển của lá}

Giá trị LAI các được phân nhóm theo phương pháp chia nhóm của Setiyono et al. (2019) với 49 khoảng giá trị, Các khoảng giá trị này được chuyển đổi thành khoảng giá trị RGRL Max và RGRL Min.

Giá trị RGRL MIN biểu thị tốc độ tăng trưởng tương đối tối thiểu của diện tích lá, RGRL MAX là tốc độ tăng trưởng tương đối tối đa của diện tích lá. Giá trị RGRL MIN, MAX được tính để làm dữ liệu đầu vào cho tập tin RERUN trong mô hình Oryza. RGRL được tính theo công thức của Setiyono et al. (2019) ở phương trình (1).

$$
\mathrm{RGRL}=\lambda /\left(1+\mathrm{e}^{(-\mathrm{L}-\rho) / \psi}\right)
$$

Trong đó: L là giá trị Max hoặc Min của giá trị LAI trong mỗi nhóm. $\lambda, \rho, \psi$ là các tham số hàm logistic với các giá trị mặc định lần lượt là 0.00964 , 0.52435 và 0.45271 . Các tham số này được xác định dựa trên việc đo đạc thực nghiệm tại các địa điểm nghiên cứu Setiyono et al. (2019). Tính linh hoạt này của chức năng RGRL so với LAI cho phép mang lại năng suất tương ứng đáp ứng để thích ứng với phạm vi LAI khác nhau.

\subsection{Mô hình Oryza2000}

Theo Bouman et al. (2001), mô hình Oryza sử dụng dữ liệu thời tiết hằng ngày để ước đoán, thời gian sinh trưởng của cây lúa, thời gian bắt đầu các giai đoạn sinh trưởng, chỉ số LAI biến động trong cả thời kỳ sinh trưởng; dữ liệu về đất, dữ liệu quản lý cây trồng (tưới nước, phân bón,...) các yếu tố này là yếu tố đầu vào cho mô hình Oryza để ước đoán năng suất.

Để chạy mô hình ước đoán năng suất ngoài dữ liệu thời tiết còn cần một số dữ liệu khác như dữ liệu đất, dữ liệu cây trồng gồm đặc tính đất và dữ liệu 
giống lúa. Đối với giống lúa, tỉnh An Giang sử dụng nhiều loại giống khác nhau trong đó thời gian sinh trưởng trung bình từ 95-100 ngày. Do đó mô hình sử dụng giống lúa ngắn ngày (95-100 ngày) theo định nghĩa của Oryza.

Thiết lập tập tin Rerun cho phép chạy mô phỏng năng suất ở nhiều điểm. Như vậy mỗi điểm mô phỏng ứng với 1 khoảng giá trị RGRL. Trạm thời tiết lưu tập tin ký hiệu 456182, phương pháp canh tác trong tập tin YASTNDRD.DAT và giống lúa được định nghĩa trong tập tin MVshort.DAT của Oryza. Thời điểm bắt đầu chạy mô hình là ngày 1 tháng 5 năm 2018 (ngày thứ 121 trong năm 2018).

Dữ liệu đầu ra với biến WRR14 là năng suất hạt với $14 \%$ độ ẩm được sử dụng để xây dựng bản đồ năng suất.

\subsection{Hiệu chỉnh và kiểm định mô hình ước đoán năng suất lúa}

Năng suất mô phỏng từ mô hình được tính toán lại theo từng huyện và so sánh với dữ liệu năng suất thực tế theo giá trị sai số trung phương RMSE theo Kenney \& Keeping (1962) như phương trình (2). Chỉ số đánh giá này được (Hyndman \& Koehler, 2006) khuyến cáo sử dụng trong đánh giá sai số của giá trị không âm.

$$
\mathrm{RMSE}=\sqrt{\frac{\sum_{t=1}^{T}\left(y_{h}-y_{m p}\right)^{2}}{T}}
$$

Trong đó: $y_{m p}$ là năng suất mô phỏng ở huyện t; $y_{h}$ là năng suất thống kê ở huyện t; $\mathrm{T}$ là số huyện trong tỉnh (An Giang có 11 huyện).

Chỉ số nRMSE được sử dụng để đánh giá tỷ lệ phần trăm sai số mô phỏng so với trung bình quan sát thực tế Mentaschi et al. (2013). Chỉ số này được sử dụng trong nhiều nghiên cứu, gần đây của (Nguyễn Ngọc Khánh và ctv., 2020) cũng đã dùng chỉ số này đánh giá kết quả mô phỏng năng suất bắp lai ở vùng ĐBSCL.

$$
\mathrm{nRMSE}=\frac{R M S E}{Y_{t b}} x 100 \%
$$

Trong đó: RMSE sai số trung phương giữa năng suất mô phỏng và thực tế; $Y_{\mathrm{tb}}$ là năng suất trung bình thực tế.

RMSE gần 0 cho thấy mô hình mô phỏng tốt giá trị quan sát (Jacovides \& Kontoyiannis, 1995). Một sự mô phỏng có thể được coi là rất tốt nếu nRMSE nhỏ hơn $10 \%$, tốt nếu từ 10 đến $20 \%$, khá nếu từ 20 đến $30 \%$ và kém nếu lớn hơn $30 \%$ (van Ruijven et al., 2010).
Các tham số $\lambda, \rho, \psi$ được hiệu chỉnh tự động nhằm tìm ra giá trị tham số $\lambda$ thích hợp. Trong đó tham số $\lambda$ được hiệu chỉnh bằng cách nhân giá trị $\lambda$ lần lượt với các hệ số bằng hệ số 0.1 đến 1 , mỗi giá trị hiệu chỉnh được sử dụng để chạy mô hình Oryza2000 và tính RMSE giữa năng suất mô phỏng và năng suất thực tế. Giá trị tham số với RMSE nhỏ nhất trong thử nghiệm sẽ sử dụng để mô phỏng năng suất cho các vụ còn lại. RMSE được tính

Các hệ số thực nghiệm $\lambda, \rho, \psi$ sau khi hiệu chỉnh được sử dụng để chạy kiểm chứng mô hình ước đoán năng suất lúa ở các vụ Thu Đông 2018, Đông Xuân 2019 và Hè Thu 2019.

\section{KẾT QUẢ VÀ THẢO LUẬN}

\subsection{Bản đồ đột sạ}

\subsubsection{Bản đồ chi số LAI theo đợt sạ}

Đối với cây lúa, sự biến động của năng suất và sản lượng có sự ảnh hưởng rất lớn của các yếu tố khí tượng và thủy văn (Nguyễn Văn Viết và ctv., 2002). Vì vậy, thời gian gieo sạ có ảnh hưởng lớn đến sự biến động của năng suất và sản lượng lúa. Để tập trung nghiên cứu việc ứng dụng ảnh MODIS LAI trong ước đoán năng suất lúa, bản đồ đợt sạ sử dụng từ nguồn phần mềm MapScape 5.5. Kết quả thu thập là bản đồ đợt sạ tỉnh An Giang trong 2 năm 2018 và 2019 bao gồm 4 vụ: vụ Hè Thu năm 2018, vụ Thu Đông năm 2018, vụ Đông Xuân năm 2019 và vụ Hè Thu năm 2019 (Hình 2). Các bản đồ đợt sạ được phân chia thành 20 đợt theo phần mềm MapScape, mỗi đợt cách nhau 6 ngày ứng với 120 ngày.

Qua bản đồ ngày gieo sạ vụ Hè Thu 2018 (Hình 2a) có diện tích gieo sạ lúa trong vụ không đồng loạt, tập trung chủ yếu vào 2 giai đoạn: giai đoạn đầu vụ (từ ngày 05 tháng 02 đến ngày 01 tháng 03 ). Bản đồ đợt sạ vụ Thu Đông (Hình $2 \mathrm{~b}$ ) cho thấy thời gian gieo sạ trong vụ có sự đồng nhất cao, cụ thể phần lớn diện tích gieo sạ rơi vào ngày 06 tháng 05 đến ngày 18 tháng 05 . Tuy nhiên, huyện Phú Tân, huyện Tri Tôn và Long Xuyên có một phần diện tích có thời gian gieo sạ chậm hơn (từ ngày 23 tháng 06 đến ngày 10 tháng 07 ). Theo bản đồ đợt sạ vụ ĐôngXuân năm 2018-2019 (Hình 2c), huyện Tri Tôn, Tịnh Biên, Long Xuyên, An Phú là những huyện có phần lớn diện tích lúa gieo sạ sớm (chủ yếu từ ngày 21 tháng 10 đến ngày 08 tháng 11 ). Trễ hơn là các huyện Thoại Sơn, Châu Thành, Châu Phú, Châu có phần lớn diện tích gieo sạ lúa từ ngày 08 tháng 12 đến ngày 26 tháng 12. Trong vụ Hè Thu năm 2019 (Hình $2 \mathrm{~d}$ ), phần lớn diện tích lúa được gieo sạ vào các đợt sạ giữa vụ (từ ngày 13 tháng 04 đến ngày 01 tháng 05). 


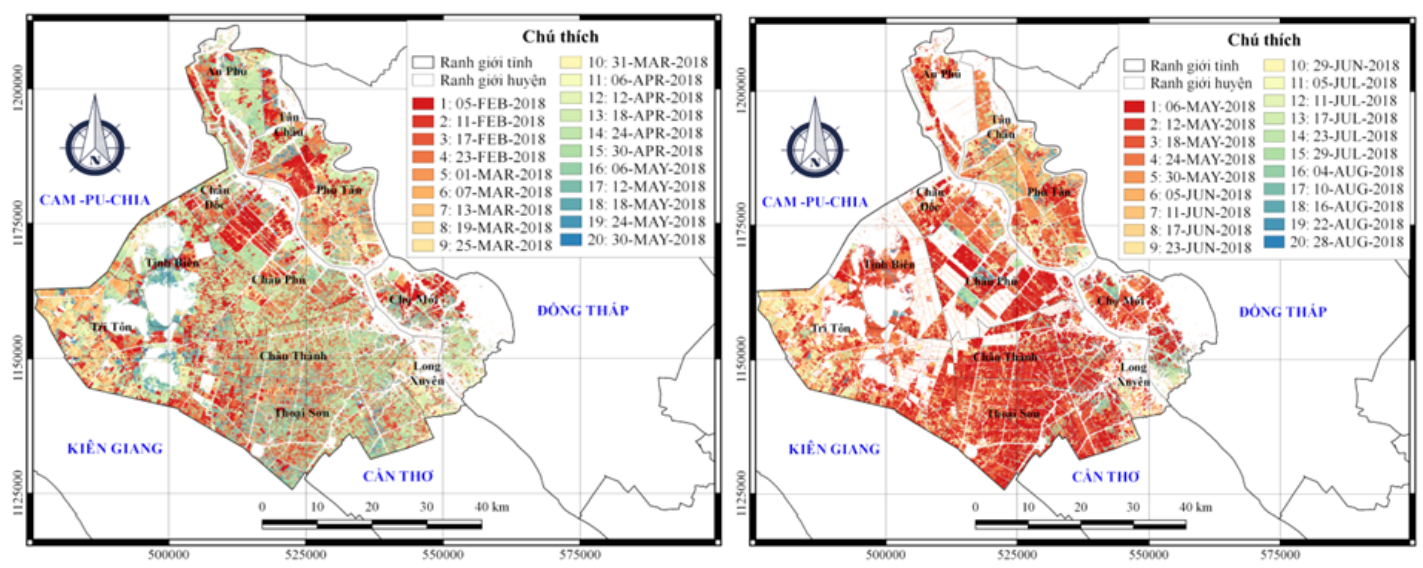

a)

b)

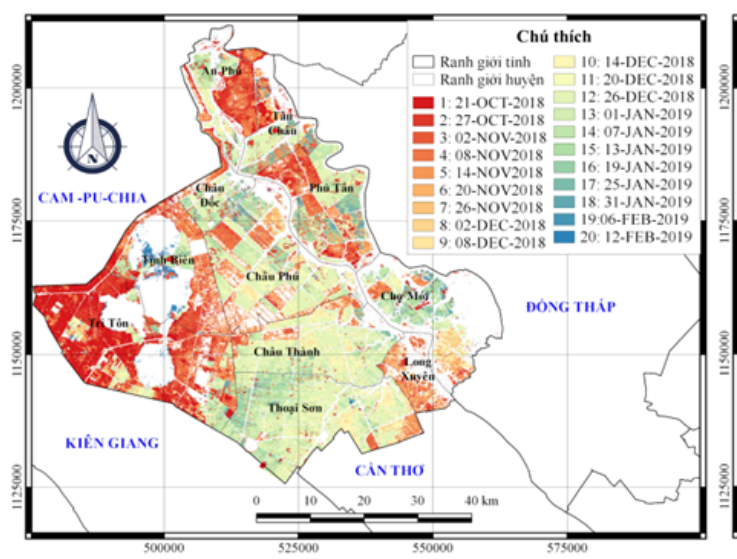

c)

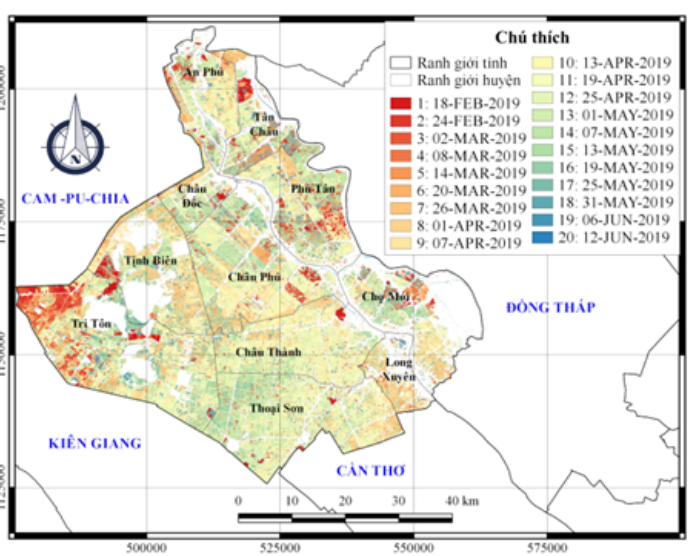

d)

Hình 2. Bản đồ đột sạ từ phần mềm MapScape tỉnh An Giang

a) Vụ Hè Thu 2018; b) Vu Thu Đông 2018; c) Vụ Đông Xuân 2019; d) Vụ Hè Thu 2019

\subsubsection{Dũ liệu thời tiết tù̀ thiết bị IOT}

Dũ liệu khí hậu tỉnh An Giang trong 2 năm 20182019 bao gồm giá trị hằng ngày các yếu tố về nhiệt độ trung bình, tổng số giờ nắng, tổng lượng mưa và áp suất không khí. Do thiết bi IOT được đưa vào sử dụng năm 2019 nên số liệu thời tiết thu thập được của năm 2019. Năm 2018 sử dụng dữ liệu thời tiết lịch sử.

Nhiệt độ trung bình trong khoảng từ 25,9 đến $28,8^{\circ} \mathrm{C}$, nhiệt độ thấp nhất rơi vào những ngày cuối tháng 01 đầu tháng 02 , nhiệt độ cao nhất vào những ngày giữa tháng 04 và tháng 05 trong khoảng 28,8 đển $28,6^{\circ} \mathrm{C}$. Nhìn chung biên độ nhiệt trong ngày trong khoảng dưới $10^{\circ} \mathrm{C}$.

Tổng lượng mưa trong năm phân bố không điều (Hình $3 \mathrm{a}, 3 \mathrm{c}$ ), phân chia thành 2 mùa rõ rệt là: mùa mưa và mùa khô. Tổng lượng mưa cao nhất vào giai đoạn mùa mưa, giai đoạn này thường bắt đầu vào đầu tháng 5 và kết thúc vào cuối tháng 12 , lượng mưa thấp vào mùa khô, giai đoạn mùa khô bắt đầu từ cuối tháng 1 đến hết tháng 4 .

Độ ẩm không khí trung bình năm cao từ 76,5\% đến $85,2 \%$ (Hình $3 \mathrm{~b}, 3 \mathrm{~d}$ ). Tháng 12 năm 2018 và tháng 4 năm 2019 có độ ầm thấp nhất với giá trị độ ẩm trung bình là $78,7 \%$ và $76,5 \%$, độ ẩm cao nhất rơi vào tháng 5 năm 2018 và tháng 6 năm 2019 với giá trị $85,2 \%$. Vào mùa khô (tháng 1 đến tháng 5 ) ở cả 2 năm tổng số giờ nắng có giá trị lớn hơn giai đoạn mùa mưa (tháng 5 đến tháng 9). Tuy nhiên vào giai đoạn cuối mùa mưa (tháng 10 đến tháng 12 ) tuy thời tiết vẫn còn mưa nhưng tổng số giờ nắng trong tháng có giá trị lớn hơn đầu mùa. 


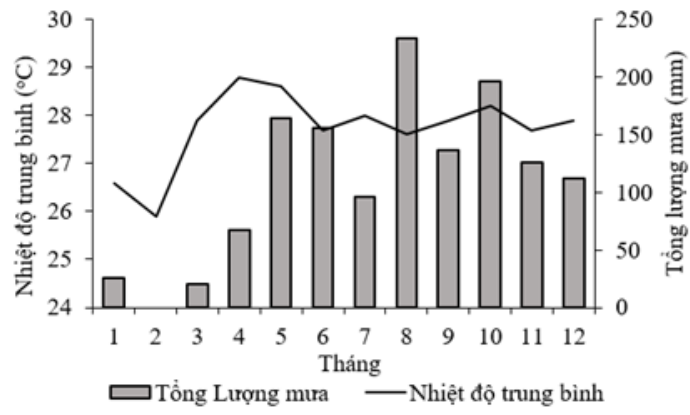

a)

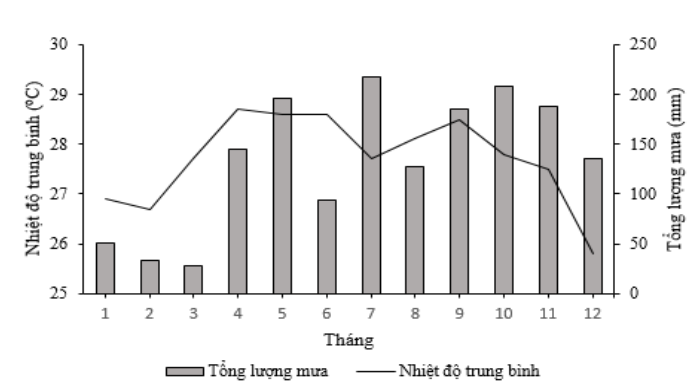

c)

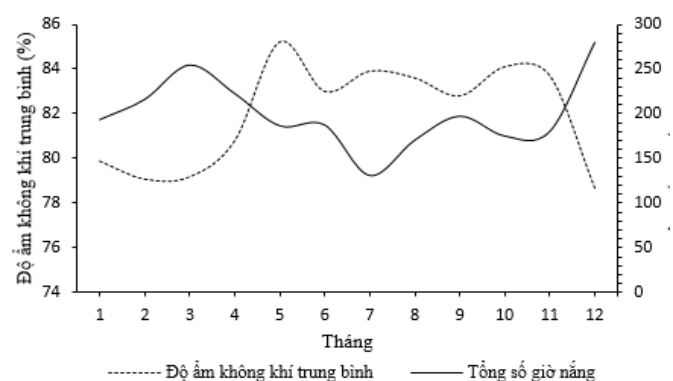

b)

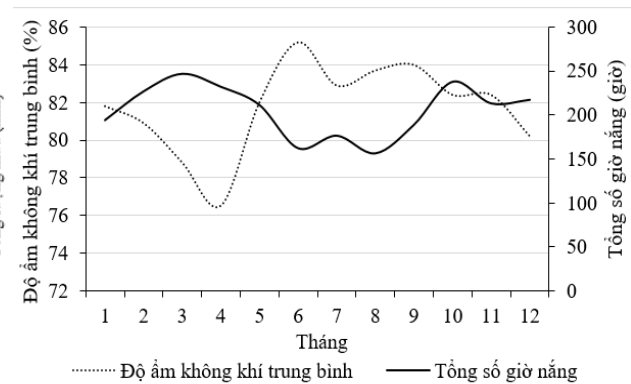

d)

Hình 3. Biểu đồ dữ liệu thời tiết Tỉnh An Giang năm 2018 - 2019

a) Nhiệt độ, lương mura 2018; b) Độ ẩm không khí, số giờ nắng 2018

c) Nhiệt độ, lượng mura 2019; b) Độ ẩm không khí, số giờ nắng 2019

\subsection{Bản đồ chỉ số diện tích lá từ ảnh MODIS}

Quá trình quang hợp là hoạt động tích lũy cơ bản tạo ra năng suất. Trong quá trình này, lá là bộ phận cực kì quan trọng, là cơ quan quang hợp chủ yếu của cây lúa. Diện tích lá có ảnh hưởng mạnh mẽ đến quá trình quang hợp và tích lũy năng suất cho cuối vụ. Ước tính chính xác, khách quan chỉ số diện tích lá là tham số quan trọng trong mô hình dự đoán năng suất lúa (Jonckheere et al., 2004). Kết quả tổng hợp bản đồ LAI ở $1 / 3$ thời gian sinh trưởng của các vụ trong năm 2018 và 2019 ở An Giang được thể hiện trong Hình 4.

Vụ Hè Thu năm 2018 bắt đầu gieo sạ vào tháng $02 / 2018$ và kết thúc vào cuối tháng $05 / 2018$. Thời điểm này là thời điểm chuyển giao giữa mùa khô và mùa mưa, tại những vị trí có mưa sớm hoặc có đủ nguồn nước tưới người dân bắt đầu gieo sạ. Hình $4 \mathrm{a}$ thể hiện khoảng giá trị LAI từ $0,1 \mathrm{~m}^{2} \mathrm{lá} / \mathrm{m}^{2}$ đất đến $0,5 \mathrm{~m}^{2} \mathrm{lá} / \mathrm{m}^{2}$ đất chiếm tỉ lệ không nhiều. Giá trị LAI cao trên $6,5 \mathrm{~m}^{2}$ lá $/ \mathrm{m}^{2}$ đấttại các huyện Châu Phú, Tịnh Biên và An Phú. Vùng Châu Thành,
Thoại Sơn, Tri Tôn chứa giá trị LAI trung bình (từ $1,5 \mathrm{~m}^{2}$ lá $/ \mathrm{m}^{2}$ đất đến $3,5 \mathrm{~m}^{2} \mathrm{lá} / \mathrm{m}^{2}$ đất).

Vụ Thu Đông, được gieo sạ ngay sau khi kết thúc vụ Hè Thu nên rơi vào giai đoạn cuối mùa mưa nên có được lượng nước tưới dồi dào. Hình $4 \mathrm{~b}$ thể hiện sự phân bố giá trị LAI trong không gian, giá trị LAI toàn vụ phân bố không đồng điều cao nhất (trên 6,5 $\mathrm{m}^{2}$ lá $/ \mathrm{m}^{2}$ đất) và thấp nhất $\left(0,1 \mathrm{~m}^{2}\right.$ lá $/ \mathrm{m}^{2}$ đất đến 0,5 $\mathrm{m}^{2}$ lá/ $\mathrm{m}^{2}$ đất). Phần lớn khu vực canh tác lúa có giá trị LAI trên ngưỡng trung bình (từ $0,5 \mathrm{~m}^{2} l a ́ / \mathrm{m}^{2}$ đất đến $1,5 \mathrm{~m}^{2} l a ́ / \mathrm{m}^{2}$ đất và từ $3,5 \mathrm{~m}^{2}$ lá $/ \mathrm{m}^{2}$ đất đến 5 $\mathrm{m}^{2} l a ́ / \mathrm{m}^{2}$ đất).

Vụ Đông Xuân là vụ đem lại năng suất cao, được canh tác trong điều kiện khí hậu, thời tiết thuận lợi. Do đó, giá trị LAI vụ Đông Xuân năm 2019 tỉnh Án Giang tương đối cao (Hình $4 \mathrm{c}$ ). Trong đó, các huyện Thoại Sơn, Châu Thành có hơn $90 \%$ diện tích có giá trị LAI trên $6,5 \mathrm{~m}^{2} \mathrm{lá} / \mathrm{m}^{2}$ đất. Tri Tôn và Tịnh Biên có xuất hiện khu vực mang giá trị LAI thấp (từ 0,1 $\mathrm{m}^{2}$ lá $/ \mathrm{m}^{2}$ đất đến $0,5 \mathrm{~m}^{2} \mathrm{lá} / \mathrm{m}^{2}$ đất) với diện tích khá đáng kể, tuy nhiên nhìn chung tỷ lệ giá trị LAI cao vẫn chiếm đa số. 


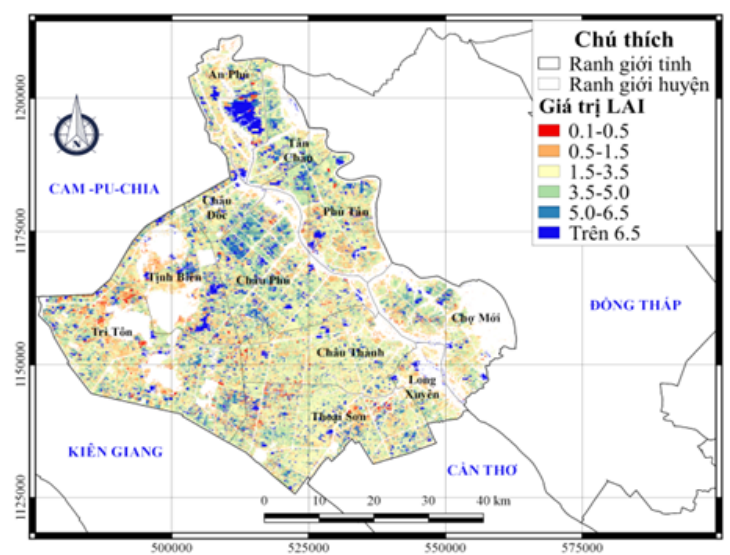

a)

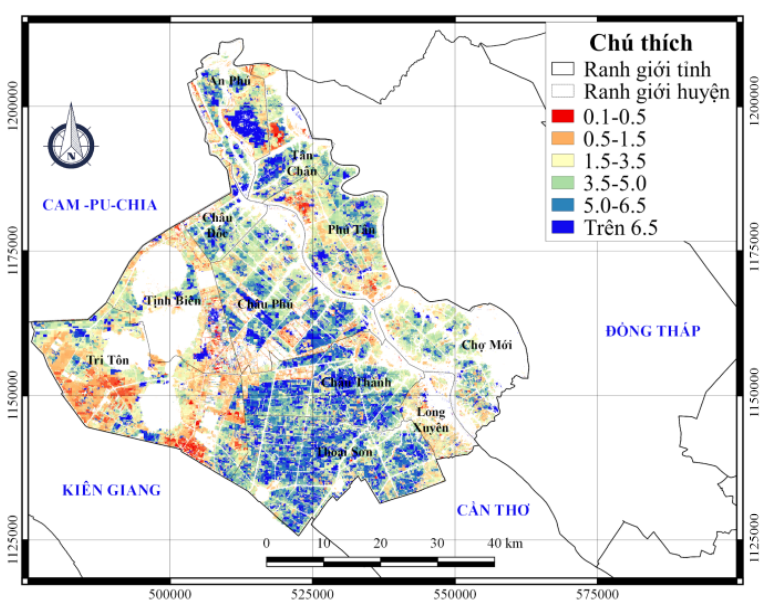

c)

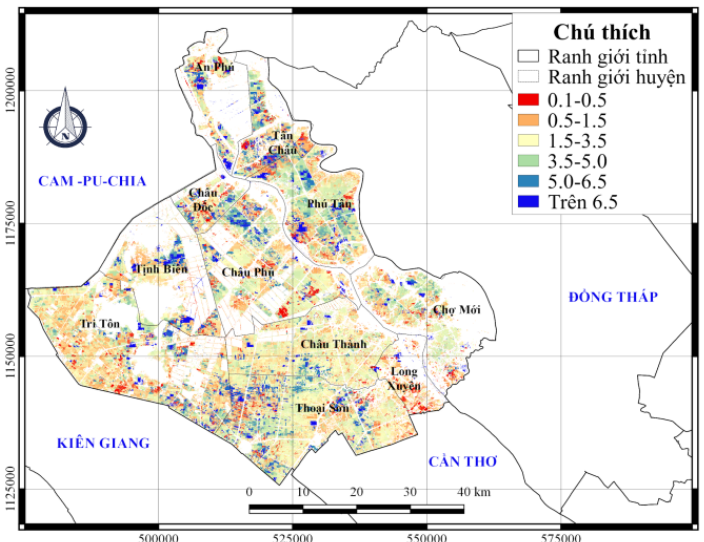

b)

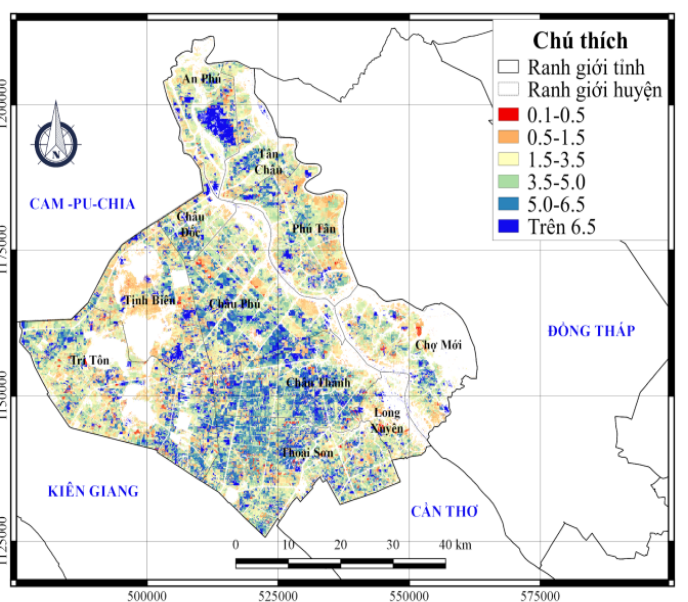

d)

Hình 4. Bản đồ tổng hợp LAI 30 đến 40 ngày sau sạ tỉnh An Giang

a) Hè Thu 2018; b) Thu Đông 2018; c) Đông Xuân 2019; d) Hè Thu 2019

Vụ Hè Thu được gieo sạ ngay phía sau khi kêt thúc vụ Đông Xuân. Kết quả phân tích bản đồ LAI 30 ngày sau sạ của vụ (Hình $4 \mathrm{~d})$ cho thấy, giá trị LAI trong vụ này dao động từ $0,1 \mathrm{~m}^{2} l a ́ / \mathrm{m}^{2}$ đất đến trên 6,5 $\mathrm{m}^{2} \mathrm{lá} / \mathrm{m}^{2}$ đất, tuy nhiên khoảng giá trị từ 0,1 $\mathrm{m}^{2} \mathrm{lá} / \mathrm{m}^{2}$ đất đến $0,5 \mathrm{~m}^{2}$ lá $/ \mathrm{m}^{2}$ đất chiếm tỉ lệ không nhiều xuất hiện chủ yếu chỉ xuất hiện tại huyện Chợ Mới, Long Xuyên và huyện Tịnh Biên. Vùng chứa giá trị LAI cao nhất bao gồm các huyện: An Phú, Châu Phú, Châu Thành, Thoại Sơn với giá trị chỉ số diện tích lá trên $6,5 \mathrm{~m}^{2}$ lá $/ \mathrm{m}^{2}$ đất. Các khu vực còn lại của tỉnh phần lớn đều có giá trị LAI từ 1,5 $\mathrm{m}^{2}$ lá $/ \mathrm{m}^{2}$ đất đến $3,5 \mathrm{~m}^{2}$ lá $/ \mathrm{m}^{2}$ đất (huyện Tri Tôn, huyện Phú Tân), giá trị LAI từ 3,5 $\mathrm{m}^{2} \mathrm{lá} / \mathrm{m}^{2}$ đất đến $5,0 \mathrm{~m}^{2} \mathrm{lá} / \mathrm{m}^{2}$ đất (huyện Thoại Sơn, Châu Đốc và Tân Châu).

\subsection{Hiệu chỉnh mô hình năng suất lúa}

Quá trình hiệu chỉnh các tham số $\lambda, \rho, \psi$ cho thấy việc hiệu chỉnh 2 tham số $\rho, \psi$ không làm thay đổi quá lớn đến giá trị RGRL Max và RGRL Min. 
Bảng 1. Kết quả tổng hợp mô phỏng năng suất lúa Hè Thu năm 2018

\begin{tabular}{lrrr}
\hline Huyện & $\begin{array}{r}\text { Năng suất thực tế } \\
\text { (tấn/ha) }\end{array}$ & $\begin{array}{r}\text { Năng suất hiệu chỉnh } \\
\text { (tấn/ha) }\end{array}$ & Độ lệch (\%) \\
\hline Long Xuyên & 5,76 & 5,62 & -2 \\
Châu Đốc & 5,60 & 6,04 & 8 \\
An Phú & 5,61 & 5,79 & 3 \\
Tân Châu & 5,84 & 6,25 & 7 \\
Phú Tân & 5,80 & 6,15 & 6 \\
Châu Phú & 5,89 & 6,03 & 2 \\
Tịnh Biên & 5,64 & 6,01 & 6 \\
Tri Tôn & 5,75 & 6,06 & 5 \\
Châu Thành & 5,71 & 5,54 & -3 \\
Chợ Mới & 5,61 & 6,09 & 9 \\
Thoại Sơn & 5,74 & 5,64 & -2 \\
\hline
\end{tabular}

Dấu "-" thể hiện cho năng suất mô phỏng thấp hơn so với thực tế

Khi hiệu chỉnh $\lambda$ với mức $0,7 \lambda(\lambda=0,006748)$ cho kết quả gần mô phỏng (Bảng 1$)$ có giá trị gần với năng suất thực tế nhất. Với giá trị RMSE là 0,31 (tấn) và nRMSE là $5,23 \%$, trong đó tất cả các huyện điều có mức năng suất mô phỏng chênh lệch dưới $10 \%$, mức độ lệch thấp nhất chỉ từ $2 \%$ (Long Xuyên, Châu Phú, Thoại Sơn) đến cao nhất là $9 \%$ (Chợ Mới).

\subsection{Kiểm chứng năng suất mô phỏng}

Giá trị tham số $\lambda$ sau hiệu chỉnh là 0,006748 được chọn để chạy mô phỏng các vụ tiếp để kiểm chứng mô hình.

Kết quả mô phỏng năng suất của các vụ Thu Đông 2018, Đông Xuân 2018-2019 và Hè Thu 2019 được thể hiện trong Bảng 2. Giá trị năng suất mô phỏng được so sánh với năng suất thống kê theo mỗi huyện.

Bảng 2. So sánh năng suất thực tế và năng suất mô phỏng ở các vụ

\begin{tabular}{|c|c|c|c|c|c|c|c|c|c|}
\hline \multirow{3}{*}{ Huyện } & \multicolumn{3}{|c|}{ Thu đông 2018} & \multicolumn{3}{|c|}{ Đông Xuân 2018- 2019} & \multicolumn{3}{|c|}{ Hè Thu 2019} \\
\hline & $\begin{array}{c}\text { Thực } \\
\text { tế }\end{array}$ & $\begin{array}{c}\text { Mố } \\
\text { phỏng }\end{array}$ & \multirow[t]{2}{*}{$\begin{array}{c}\text { nRSME } \\
(\%)\end{array}$} & Thực tế & $\begin{array}{c}\text { Mố } \\
\text { phỏng }\end{array}$ & \multirow[t]{2}{*}{$\begin{array}{c}\text { nRSME } \\
(\%)\end{array}$} & Thực tế & $\begin{array}{c}\text { Mố } \\
\text { phỏng }\end{array}$ & \multirow{2}{*}{$\begin{array}{c}\text { nRSME } \\
(\%)\end{array}$} \\
\hline & \multicolumn{2}{|c|}{ (Tấn/ha) } & & \multicolumn{2}{|c|}{ (Tấn/ha) } & & \multicolumn{2}{|c|}{ (Tấn/ha) } & \\
\hline Long Xuyên & 5,29 & 5,24 & 1 & 7,13 & 7,37 & 3 & 6,23 & 5,74 & 8 \\
\hline Châu Đốc & 5,68 & 5,43 & 4 & 7,07 & 7,35 & 4 & 5,62 & 5,54 & 1 \\
\hline An Phú & 6,09 & 5,53 & 9 & 7,15 & 7,54 & 5 & 6,00 & 5,69 & 5 \\
\hline Tân Châu & 5,89 & 5,96 & -1 & 7,31 & 7,42 & 1 & 5,74 & 5,93 & -3 \\
\hline Phú Tân & 5,90 & 5,80 & 2 & 7,51 & 7,30 & -3 & 6,07 & 5,63 & 7 \\
\hline Châu Phú & 6,19 & 5,36 & 13 & 7,60 & 7,32 & -4 & 6,02 & 5,79 & 4 \\
\hline Tịnh Biên & 5,81 & 5,75 & 1 & 6,72 & 7,36 & 10 & 5,55 & 5,72 & -3 \\
\hline Tri Tôn & 5,37 & 5,88 & -9 & 6,91 & 7,49 & 8 & 5,60 & 5,90 & -5 \\
\hline Châu Thành & 5,72 & 5,06 & 11 & 7,74 & 7,14 & -8 & 6,06 & 5,66 & \\
\hline Chợ Mới & 5,97 & 5,51 & 8 & 7,28 & 7,01 & -4 & 5,63 & 5,78 & -3 \\
\hline Thoại Sơn & 6,08 & 5,22 & 14 & 7,68 & 7,56 & -2 & 6,13 & 5,79 & 6 \\
\hline
\end{tabular}

Dấu “-” thể hiện cho năng suất mô phỏng thấp hơn so với năng suất thực tế

Kết quả ở Bảng 2 cho thấy năng suất mô phỏng vụ Thu Đông dao động từ 5,06-5,96 tấn/ha, huyện có năng suất cao nhất là huyện Tân Châu $(5,96$ tấn/ha), huyện có năng suất thấp nhất là Châu Thành $(5,06$ tấn/ha). Độ chênh lệch năng suất giữa năng suất thực tế và năng suất mô phỏng ở huyện Châu Phú, Châu Thành và Thoại Sơn cao hơn $10 \%$ (cụ thể lần lượt là $13 \%, 11 \%$ và $14 \%$ ). Các huyện Tịnh Biên, Tân Châu và Long Xuyên là các khu vực có giá trị mô phòng tốt (lệch $1 \%$ ).

Bảng 2 cũng cho thấy cho thấy năng suất mô phỏng ở vụ Đông Xuân 2019 từ 7,01-7,56 tấn/ha. Giá trị chênh lệch giữa thực tế và mô phỏng chủ yếu 
từ $1 \%$ đến $10 \%$, huyện Tịnh Biên có độ lệch cao nhất $10 \%$, huyện Tân Châu độ lệch thấp nhất với $1 \%$. Vụ Hè Thu 2019 có năng suất mô phỏng của vụ từ 5,545,93 tấn/ha (Bảng 2), trong đó huyện Châu Đốc có giá trị năng suất nhỏ nhất $(5,54$ tấn/ha), cao nhất là huyện Tân Châu (5,93 tấn/ha). Độ lệch giữa năng suất thực tế và năng suất mô phỏng chủ yếu từ $1 \%$ đến $8 \%$, Thành phố Long Xuyên có mức chênh lệch cao nhất với $8 \%$, Thành phố Châu Đốc có độ lệch thấp nhất là $1 \%$ (Bảng 2).

Phân tích kết quả mô phỏng năng suất vụ Thu Đông 2018 (Hình 5) cho thấy, năng suất mô phỏng cao ở một phần phía Bắc huyện Phú Tân và vùng giáp Biên giới huyện Tri Tôn $(6,60-7,00$ tấn/ha). Các huyện Châu Thành, Thoại Sơn, Châu Đốc, phía Nam Chợ Mới và Châu Phú, khu giáp tỉnh Đồng Tháp của huyện Phú Tân có năng suất thấp $(4,80-$ 5,70 tấn/ha). Năng suất mô phỏng trong vụ có sự chênh lệch do nhiều nguyên nhân như: sai số của số liệu thống kê, sai số của số liệu thu thập (số liệu đất, khí tượng), chế độ quản lý nước và phân bón. Tuy nhiên, với giá trị RMSE là 0,44 (tấn) và nRMSE cho toàn tỉnh là $5,61 \%$ thì mô phỏng được xem là rất tốt (van Ruijven et al., 2010), do đó kết quả mô phỏng năng suất trong vụ này hoàn toàn có ý nghĩa.

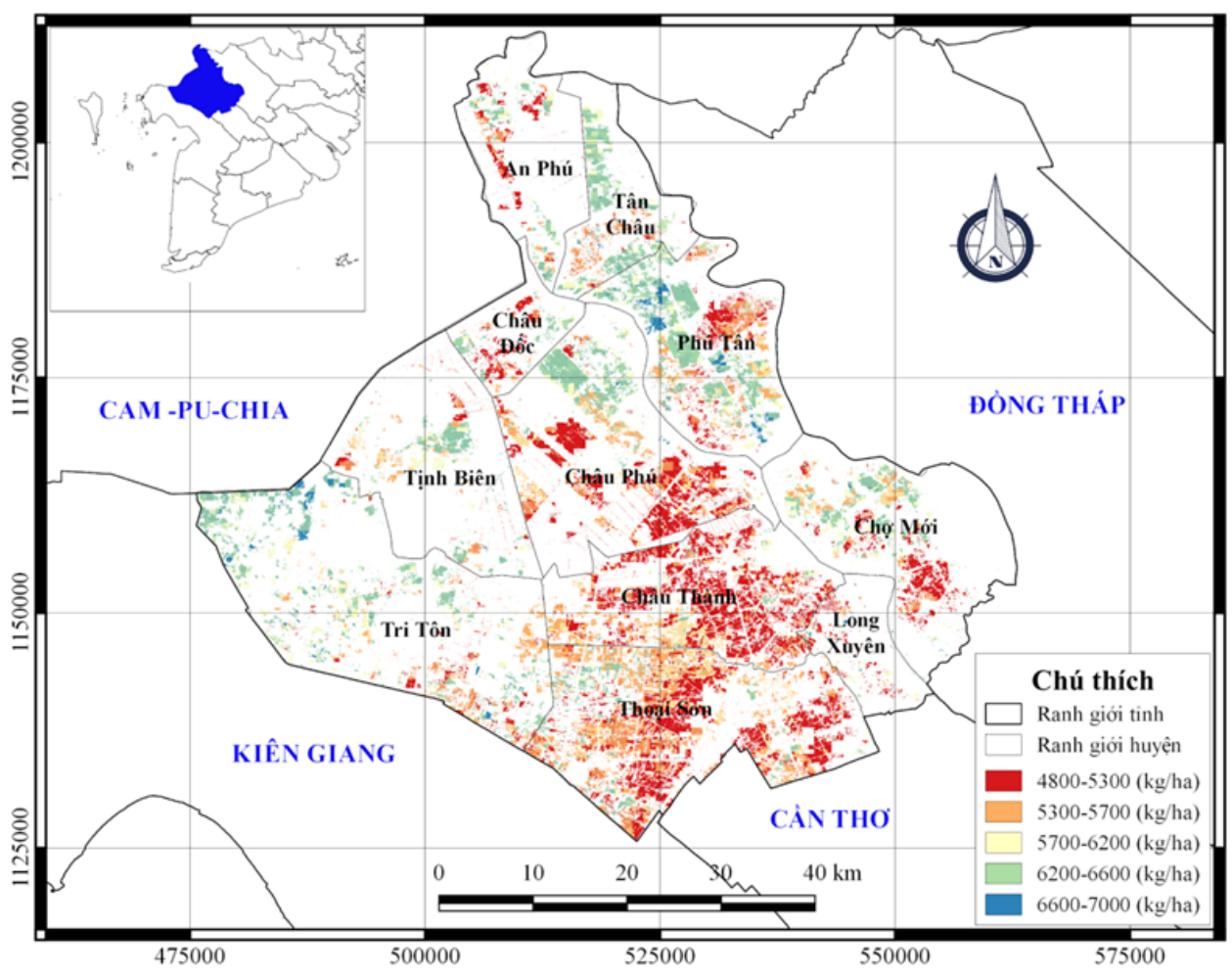

Hình 5. Bản đồ năng suất vụ Thu Đông tỉnh An Giang năm 2018

Vụ Đông Xuân có điều kiện khí hậu thuận lợi, lượng mưa và số giờ nắng vừa đủ, nhiệt độ trung bình phù hợp cho cây lúa phát triển tốt, năng suất lúa của vụ phần lớn điều cao hơn so với các vụ còn lại.

Bản đồ năng suất mô phỏng vụ Đông Xuân 2018-2019 (Hình 6) cho thấy phần lớn diện tích canh tác lúa trong vụ có giá trị năng suất cao (hơn 80\% tổng diện tích canh tác). Các huyện Châu Phú, Châu Thành, Thoại Sơn, Chợ Mới, TP. Châu Đốc là những khu vực canh tác lúa đạt năng suất cao nhất khoảng 7,80-8,20 tấn/ha, các khu vực đất canh tác còn lại điều có mức năng suất lúa trung bình từ 7,00 7,80 tấn/ha. Với giá trị RMSE là 0,38 (tấn) và nRMSE là $4,22 \%$ cho thấy mô phỏng rất tốt (van Ruijven et al., 2010), kết quả mô phỏng năng suất trong vụ có ý nghĩa, điều này cho thấy khả năng sử dụng của mô hình Oryza2000 trong ước đoán năng suất lúa tại vùng canh tác của tỉnh An Giang trọng vụ Đông Xuân. 


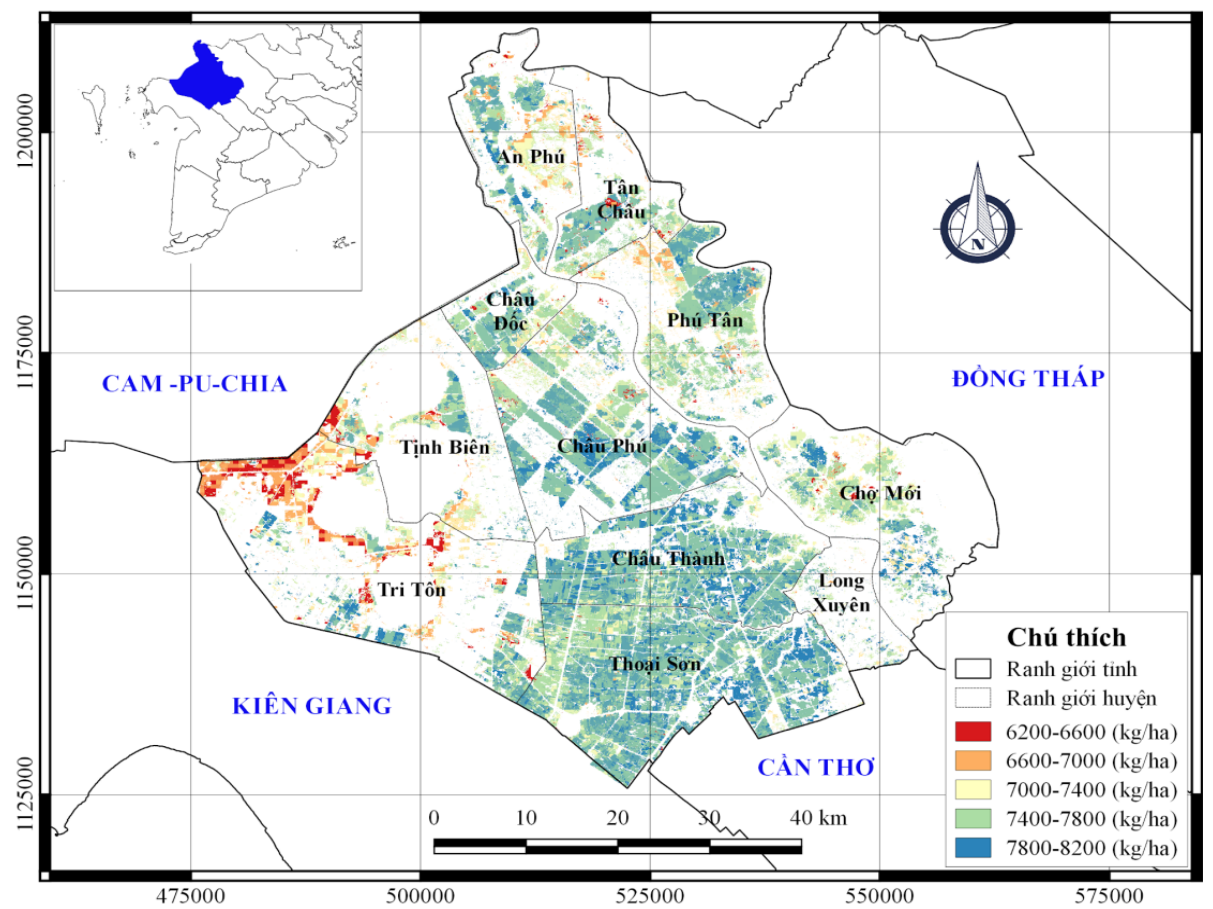

Hình 6. Bản đồ năng suất vụ Đông Xuân tỉnh An Giang năm 2018-2019

Kết quả mô phỏng năng suất của vụ Hè Thu 2019 (Hình 7) cho thấy, giá trị năng suất của vụ phân bố tương đối đồng đều. Khoảng giá trị năng suất lớn từ $6,70-7,10$ tấn/ha và khoảng giá trị năng suất nhỏ từ 5,50-5,80 tấn/ha cùng có sự phân chia nhỏ lẻ trên phạm vi toàn tỉnh. Khoảng giá trị năng suất trung bình từ 5,80-6,40 tấn/ha chiếm tỷ lệ lớn nhưng không tập phân bố tập trung, chia điều thành các vùng khác nhau. Kết quả mô phỏng năng suất trong vụ Hè Thu 2019 rất tốt với giá trị RMSE tính toán là 0,31 (tấn) giá trị hiệu chỉnh nRMSE là 5,40\% (van Ruijven et al., 2010).

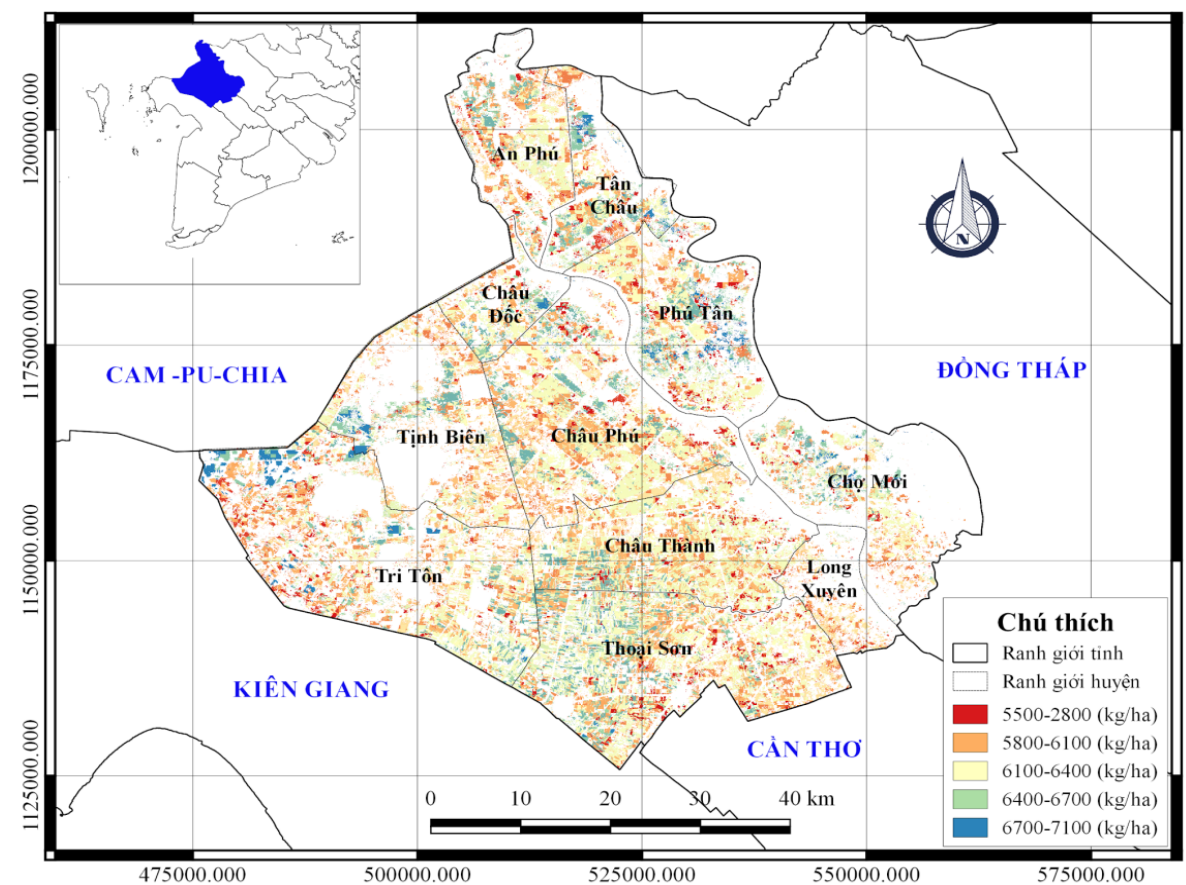

Hình 7. Bản đồ mô phỏng năng suất vụ Hè Thu năm 2019, tỉnh An Giang 


\section{5. Đánh giá kết quả mô phỏng của mô hình}

Kết quả phân tích giá trị năng suất mô phỏng từ mô hình Oryza2000 cho thấy, trong điều kiện tự nhiên thuận lợi như vụ Đông Xuân 2019 kết quả mố phỏng năng suất có giá trị cao đạt 7,00-7,56 tấn/ha, mức khác biệt giá trị năng suất RMSE là 0,383 tấn và mức hiệu chỉnh khác biệt nRMSE là $4,22 \%$. Vụ Hè Thu trong 2 năm 2018 và 2019 có năng suất mô phỏng lần lượt là $5,62-6,25$ tấn/ha và $5,54-5,99$ tấn/ha mức khác biệt năng suất so với thực tế RMSE là 0,31 tấn cho cả 2 vụ, giá trị hiệu chỉnh mức khác biệt năng suất lần lượt là $5,23 \%$ và $5,40 \%$. Kết quả mô phỏng cũng chứng minh cho quá trình hiệu chỉnh tham số $\lambda$ của mô hình có thể làm giảm sự chênh lệch khi mô phỏng năng suất so với năng suất thực tế.

\section{KẾT LUẬN}

Nghiên cứu đã thành lập bản đồ LAI tổng hợp cho cây lúa ở giai đoạn $1 / 3$ chu kỳ sinh trưởng dựa vào nguồn ảnh MODIS LAI và mô phỏng năng suất lúa đến từng pixcel dựa trên bản đồ LAI đã tổng hợp.

Kết quả mô phỏng năng suất cho thấy giá trị năng suất của các vụ lần lượt là: vụ Hè Thu 2018 đạt 5,62-6,25 tấn/ha, vụ Thu Đông 2018 đạt 5.06-5.96 tấn/ha, vụ Hè Thu 2019 đạt 5,54-5,99 tấn/ha, năng suất mô phỏng cao nhất là vào vụ Đông Xuân 2019 với giá trị mô phỏng đạt 7,00-7,56 tấn/ha. Năng suất mô phỏng trong các vụ điều có sự khác biệt so với năng suất thực tế với các giá trị RMSE và $\mathrm{nRMSE}$ tính toán trong các vụ lần lượt là: Hè Thu 2018 (RMSE là 0,31 tấn, nRMSE là 5,23\%), Thu Đông 2018 (0,44 tấn, 5,61\%), Vụ Đông Xuân 2019 (0,38 tấn, 4,22\%), Hè Thu 2019 (0,31 tấn, 5,40\%).

Trong phạm vi nghiên cứu của đề tài, quá trình hiệu chỉnh giá trị tham số $\lambda$ xuống $30 \%$ khi chuyển đổi giá trị LAI sang giá trị RGRL có thể làm tăng độ tin cậy của năng suất mô phỏng. Đây cũng là điểm mới của đề tài so với những nghiên cứu trước đây.

Với dữ liệu LAI chi tiết đến pixel nhưng dữ liệu đầu vào khác của mô hình như thời tiết, phương thức canh tác, giống lúa, đất được dùng chung cho cả tỉnh nên kết quả nghiên cứu còn hạn chế. Tuy nhiên với kết quả đạt được cho thấy ảnh viễn thám MODIS LAI hoàn toàn có thể sử dụng để trích xuất chỉ số diện tích lá (LAI) và làm đầu vào cho mô hình ước đoán năng suất lúa Oryza.

\section{LỜI CẢM TẠ}

Nguồn kinh phí thực hiện nghiên cứu được tài trợ bởi Đề tài cấp Trường mã số T2019-51. Nhóm tác giả chân thành cảm ơn Trường Đại học
Cần Thơ đã tài trợ kinh phí để thực hiện nghiên cứu này.

\section{TÀI LIỆU THAM KHẢO}

Bouman, B. A. M., Kropff, M., Tuong, T., Wopereis, M., ten Berge, H., \& van Laar, H. (2001). ORYZA2000: Modeling lowland rice. Los Baños (Philippines). http://books.irri.org/9712201716_content.pdf

Bréda, N. J. J. (2003). Ground-based measurements of leaf area index: A review of methods, instruments and current controversies. Journal of Experimental Botany, 54(392), 2403-2417. https://doi.org/10.1093/jxb/erg263

Holecz, F., Barbieri, M., Collivignarelli, F., Gatti, L., Nelson, A., Setiyono, T., Boschetti, M., Manfron, G., Brivio, P., Quilang, E., Obico, M., Minh, V., Kieu Diem, P., Huu, Q., Veasna, T., Intrman, A., Wahyunto, P., \& Pazhanivelan, S. (2013). An operation remote sensing based service for rice production estimation at national scale. https://doi.org/10.13140/2.1.1492.8643

Jacovides, C. P., \& Kontoyiannis, H. (1995). Statistical procedures for the evaluation of evapotranspiration computing models. Agricultural Water Management, 27(3), 365371. https://doi.org/10.1016/03783774(95)01152-9

Jonckheere, I., Fleck, S., Nackaerts, K., Muys, B., Coppin, P., Weiss, M., \& Baret, F. (2004). Review of methods for in situ leaf area index determination: Part I. Theories, sensors and hemispherical photography. Agricultural and Forest Meteorology, 121(1), 19-35. https://doi.org/10.1016/j.agrformet.2003.08.027

Dương Văn Khảm, Nguyễn Hồng Sơn, Nguyễn Hữu Quyền, Hoàng Thanh Tùng, Đỗ Thanh Tùng, \& Trịnh Thị Tâm (2011). Xây dựng mô hình dụ báo năng suất, sản luợng lúa ở Đồng bằng sông Hồng bằng dũ liệu ảnh MODIS. https://www.researchgate.net/profile/NguyenHuu-Quyen/publication/278038757

Nguyễn Ngọc Khánh, Tất Anh Thư, Trần Văn Dũng, Trần Hoài Tâm, \& Nguyễn Văn Quí. (2020). Úng dụng mô hình CERES-Maize mô phỏng năng suất bắp lai trồng trên đất phù sa ở Đồng bằng sông Cửu Long. Tạp chi Khoa học Trường Đại học Cần Tho, 56, 11-23. https://doi.org/10.22144/ctu.jsi.2020.064

Lam-Dao, N., Le-Toan, T., Apan, A. A., Bouvet, A., Young, F., \& Le-Van, T. (2009). Effects of changing rice cultural practices on $\mathrm{C}$-band synthetic aperture radar backscatter using Envisat advanced synthetic aperture radar data in the Mekong River Delta. Journal of Applied Remote Sensing, 3(1), 1-17. https://doi.org/10.1117/1.3271046 
Mentaschi, L., Besio, G., Cassola, F., \& Mazzino, A. (2013). Problems in RMSE-based wave model validations. Ocean Modelling, 72, 53-58. https://doi.org/10.1016/j.ocemod.2013.08.003

Myneni, Knyazikhin, Yuri, Park, Taejin, \& Ranga. (2015, May 11). MOD15A2H MODIS/Terra Leaf Area Index/FPAR 8-Day L4 Global 500m SIN Grid V006 [Data set]. NASA EOSDIS Land Processes DAAC. https://doi.org/10.5067/MODIS/MOD15A2H.006

Nelson, A., Setiyono, T., Rala, A. B., Quicho, E. D., Raviz, J. V., Abonete, P. J., ... \& Ninh, N. H. (2014). Towards an operational SAR-based rice monitoring system in Asia: Examples from 13 demonstration sites across Asia in the RIICE project. Remote Sensing, 6(11), 10773-10812. https://doi.org/10.3390/rs61110773

Nguyễn Văn Viết, Nguyễn Văn Liêm, Ngô Tiền Giang, \& Nguyễn Hồng Sơn. (2002). Tác động của những biến động khí hậu đến năng suất lúa Đông Xuân ở tỉnh Sơn La và giải pháp ứng phó. Tạp chí Khí tuợng Thuỷ văn, 504, 1-9.

Setiyono, T. D., Quicho, E. D., Holecz, F. H., Khan, N. I., Romuga, G., Maunahan, A., ... \& Mabalay, M. R. O. (2019). Rice yield estimation using synthetic aperture radar (SAR) and the ORYZA crop growth model: development and application of the system in South and South-east Asian countries. International Journal of Remote Sensing, 40(21), 8093-8124. https://doi.org/10.1080/01431161.2018.1547457

van Ruijven, B., van der Sluijs, J. P., van Vuuren, D. P., Janssen, P., Heuberger, P. S. C., \& de Vries, B. (2010). Uncertainty from Model Calibration: Applying a New Method to Transport Energy Demand Modelling. Environmental Modeling \& Assessment, 15(3), 175-188.

https://doi.org/10.1007/s10666-009-9200-z 